\title{
ANALYSIS OF DYNAMICS OF BUSINESS ENVIRONMENT AND THEIR IMPACT ON HUMAN RESOURCE MANAGEMENT
}

\author{
Dr Giriraj Kiradoo ${ }^{1}$ \\ ${ }^{1}$ Associate Professor-Govt. Engineering College Bikaner, Bikaner, Rajasthan, IN \\ drgiriraj@hotmail.com
}

Article History: Received: 11 January 2021; Accepted: 27 February 2021; Published online: 5 April 2021

\begin{abstract}
Human resources have played a role in managing workplace complication as the business environment is continuously changing. The latest paper reviews the positive and negative impact on the organisation's human resources resulting from the dynamics of technical, legal, political, and economic factors. The qualitative research technique applied in the study improves knowledge and systematically analyses resources. Research sheds light on how the technological environment, privatisation, globalisation, labour migration, changing social needs in the workplace and changing diversity affect the employees' work. The research paper examines the business executive's changing role in dealing with several human resource motivation activities and training to adapt changes to enhance competition effectively. Human resources are an indispensable organisational resource that needs to be adapted to changes to increase efficiency. Success and organisational efficiency depend on the knowledge, capability, and skills of human resources, which need to be reviewed and updated with a changing business environment. There is no loophole in achieving business success. The research paper noted a positive impact on organisational development owing to improved human resource talent competencies. Keywords- HRM, Competition, Training, Motivation, Business Environment, Diversity, Repulsion, Migrant Labour
\end{abstract}

\section{Introduction}

\subsection{Rationale-}

Human resources within an organisation play a critical role in managing management, control, operation, production, sales, and marketing tasks. Employees' competencies and talents assist accomplish pre-stated missions and objectives and improve competition (Noure, 2011). Technical upgrading, legal changes, political factors, and frequent external business environment shifts through the atmosphere occur. Managers need to train and support staff in managing these changes to be effectively concluded (Fuhua, 2010). The Human Resources Manager's proper support performs an influential role in enhancing their knowledge to improve productivity and services.

\subsection{Research Questions-}

- What is the significance of managing human resources' diversity in an organisation?

- What is the positive impact on employees due to external factors' management?

- What are the issues faced by employees in managing business change?

- What is the managers' role in combating changes in the external business environment?

\subsection{Objectives of the Study-}

- To analyse changes in the industry's business environment affects organisational performance.

- To Determine the positive and negative impact of the changing business environment on employee performance.

- To Establish the role of managers in managing employee behaviour and retention.

- To State the difference between traditional and modern methods of human resource management.

\section{Research methodology}

Primary and secondary research are the two types of research methods. Primary research gathers fresh and first-hand information through direct contact with respondents. Secondary data sources are collected through existing literature, articles, and books (Croom, 2010). This study gives an in-depth report on the principles and practices of the subject. Current research is carried out through secondary sources. The qualitative analysis provides in-depth information about human resources' role in managing external changes.

\section{Role of hrm in an organisation}

\subsection{Definition of HRM}

As per Boxall et al., Human Resource Management is an uninterrupted process carried out by the HR manager in determining vacancies in an organisation, optimising proper selection methods, and recruiting 
employees to support their talent and knowledge needs of the organisation. The manager performs motivation, training, and development functions to ensure that efforts are plugged in the right direction. Human resources are delegated with roles and responsibilities, so that team performance supports organisational development (Boxall, 2011).

\subsection{Traditional vs Modern HRM}

The traditional management approach has been driven to manage staff, while modern techniques are designed to manage human resources. In the old days, employees were seen as mere machines paid for work, such as robots and workers. Doaei concludes that the present scenario identifies human beings as an essential resource and is treated with high respect and dignity as a necessary part of the organisation. Modern HRM practices believe in efficiently integrating employees to handle changes in the business environment (Doaei, 2012).

\subsection{Importance of HRM in an Organisation}

Employees' role and contribution in an organisation cannot be ignored in all departments. It leads to the management of work practices and organisational goals. Ali and Akbar concluded in their studies that employees ensure customer satisfaction and enhance long-term relationships to boost profitability. It improves the overall level of productivity and customer engagement with its brand (Ali, 2013).

\section{Dynamics of business environments that affect the human resources management of business}

\subsection{Changing Techniques}

Technology has brought an overall shift in marketing and customer communication methods by rolling out software and updated technology. Technology's advancement has linked the pace of work by managing many activities with a single system. Technology also enhances human resources records and manages the financial performance of the business. It requires an overall change in individuals' skills and abilities (Kiradoo, 2011).

New inventions and innovations have taken place in technology since the Industrial Revolution. However, we all witness the unprecedented changes that have taken place over the past decade and a half. Artificial intelligence, genetic engineering, digital media, electronics fund transfer, advanced robotics, Internet on things, geo-targeting, self-driving cars, orange transplants, space flights, smartphones, and digital learning examples have set emerging trends. Technology has begun to be highly used in nearly all fields related to human life, such as education, medicine, agriculture, housing, transportation, household appliances, sports, entertainment, industry and commerce, banking and finance, social media, etc. forms. Employees working in these areas have only two options left, either updating themselves according to advanced technology or exiting the race.

\subsection{Increased Competition}

Developing and lagging countries have been working cautiously for several decades by making entrepreneurship and skill development a national vision and mission. Several Ministers are encouraging youth

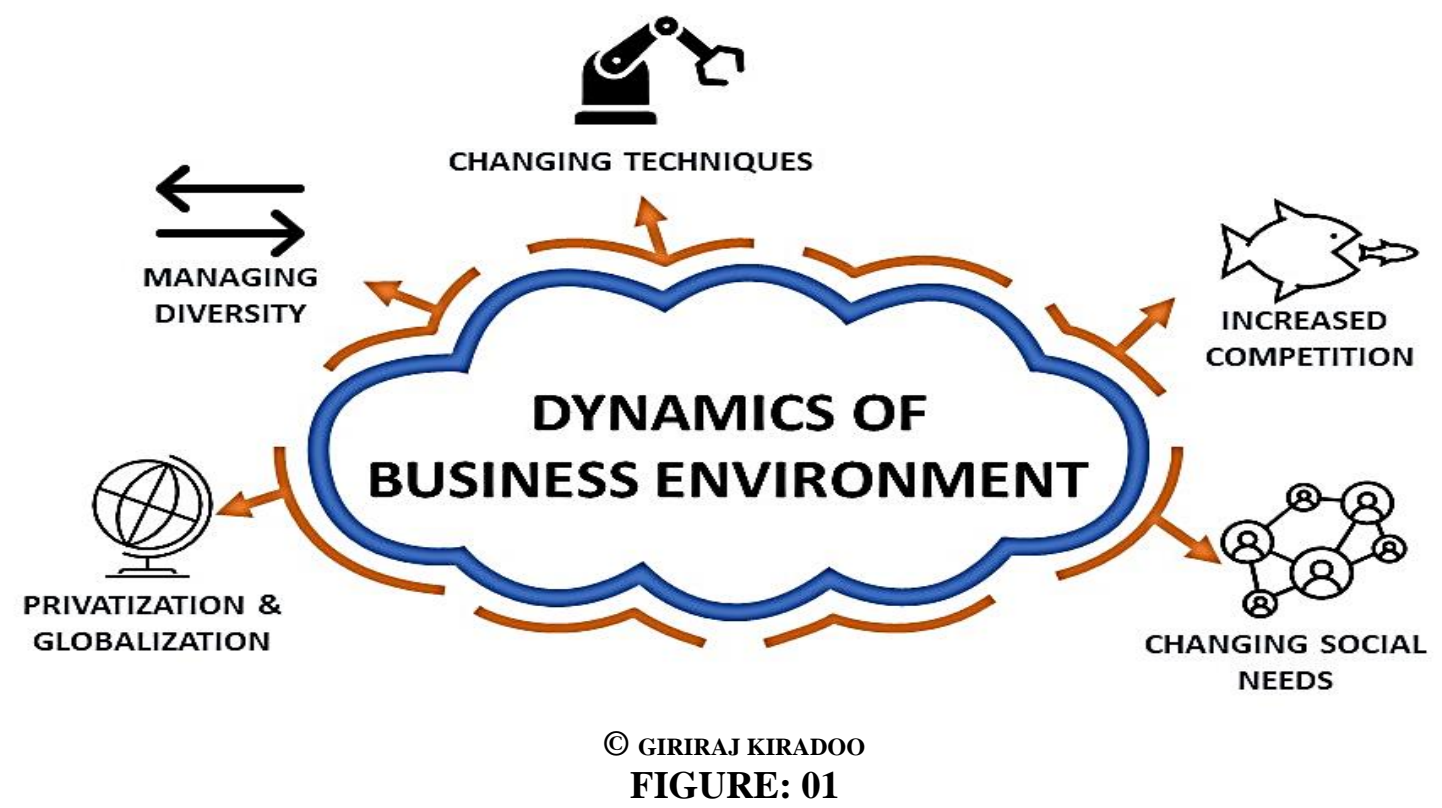


to study science and technology to set up industries and businesses by collectively working. There are many cases in India. Students with IITs, IIMs and other renowned institutions start businesses in their villages and towns with advanced technologies and innovations. Influenced by some young entrepreneurs' start-up unit, wellknown companies invest money and encourage them. These young entrepreneurs of science and technology have emerged as strong competitors in the face of classically functioning industries and enterprises. Various incentive schemes implemented by the governments have also begun to yield positive results. Educated youth are now looking forward to doing their own business instead of jobing. In such a situation, competition is increasing in the professions set up by knowledgeable young people in different areas. That is why traditional and regional enterprises are now adopting advanced techniques and innovations in their regular courses.

These steps suit the economy but are difficult for employees. Demand for a skilled labour force in business has grown immediately. In such a situation, employees working on the same pattern for a long time will have to be upgraded to face competition, which requires a great deal of training and development. This work requires excessive investment and time. In such a situation, many companies are cutting old employees to save money and time or create service conditions that automatically force them to leave their jobs.

\subsection{Changing Social Needs}

The government's positive results of India's reforms can be felt about its citizens' changing social needs from time to time. Loan schemes without interest or low interest have altered consumers' mood. Indians who have a habit of saving are adopting consumer culture by taking loans. The changing lifestyle of Indians is a testimony of this. The citizens of this country with variations are now becoming like consumers. Over the years, Indians have steadfastly adhered to foreign culture and lifestyle. They embrace global food, global language, international costume, global entertainment, and transnational family concepts.

Customers are affected by a wide range of market changes worldwide. There are changes in customer tastes and preferences that need adaptations to products and services to ensure satisfaction. Social awareness among people about sustainability and eco-friendly products has increased, affecting the organisation to bring about changes in products and services (Brown, 2011).

\subsection{Privatisation and Globalisation of Trade}

The Government of India has shown a liberal attitude towards FDI in the last five years. The government has increased the FDI limit. That is why international e-commerce firms are turning to India. Because of the growing population and their changing consumption habits, world firms consider setting up their manufacturing units in India. The Government of India has shown confidence in the private sector from government companies and PSUs' disinvestment. Handling over parts of aviation and railroads signals a significant shift to the private sectors. The reduced regulatory requirement has boosted business growth in many countries due to a growing customer base and profitability. The idea of globalising business activities requires appropriate management and personnel training to ensure diverse clients' needs and demands. Managing their response involves supporting the latest technology and constant motivation.

\subsection{Managing Diversity at the Workplace}

Fujimoto et al. said that globalisation had increased the number of employees belonging to diverse cultures, backgrounds, ethnicities, and sex. It has pressured companies to manage the diverse pool of employees through motivation, training and teamwork. The management of employee diversity plays an essential role in developing effectiveness, especially in globalised business practices (Fujimoto, 2013).

\section{Positive impact of changes in the external environment of the business on human resource development due to the adoption}

\subsection{Personal Development}

Optimising changes in the external business environment in terms of technology and customer satisfaction provide job support. It raises the possibility of employee retention and enhances knowledge for further job opportunities. There has been personal development in better living standards and satisfaction (Sarkis, 2010).

\subsection{Better Motivation}

Jackson et al. concluded that employees are highly motivated to remain connected to organisational objectives. Besides, improving overall knowledge and professional development act as a non-financial 
motivation in delivering effective services (Jackson, 2011). Employees feel motivated by aligning with their individual and organisational goals through skills due to better abilities and wide-scale risk.

\subsection{Career Growth Opportunities}

Improving skills, abilities, and knowledge support diverse growth opportunities in a person's career. They are getting far more job opportunities with increased recognition and development. Long et al. said that there is advancement in individuals' career opportunities through adjustments with the external environment and skill development (Long, 2012).

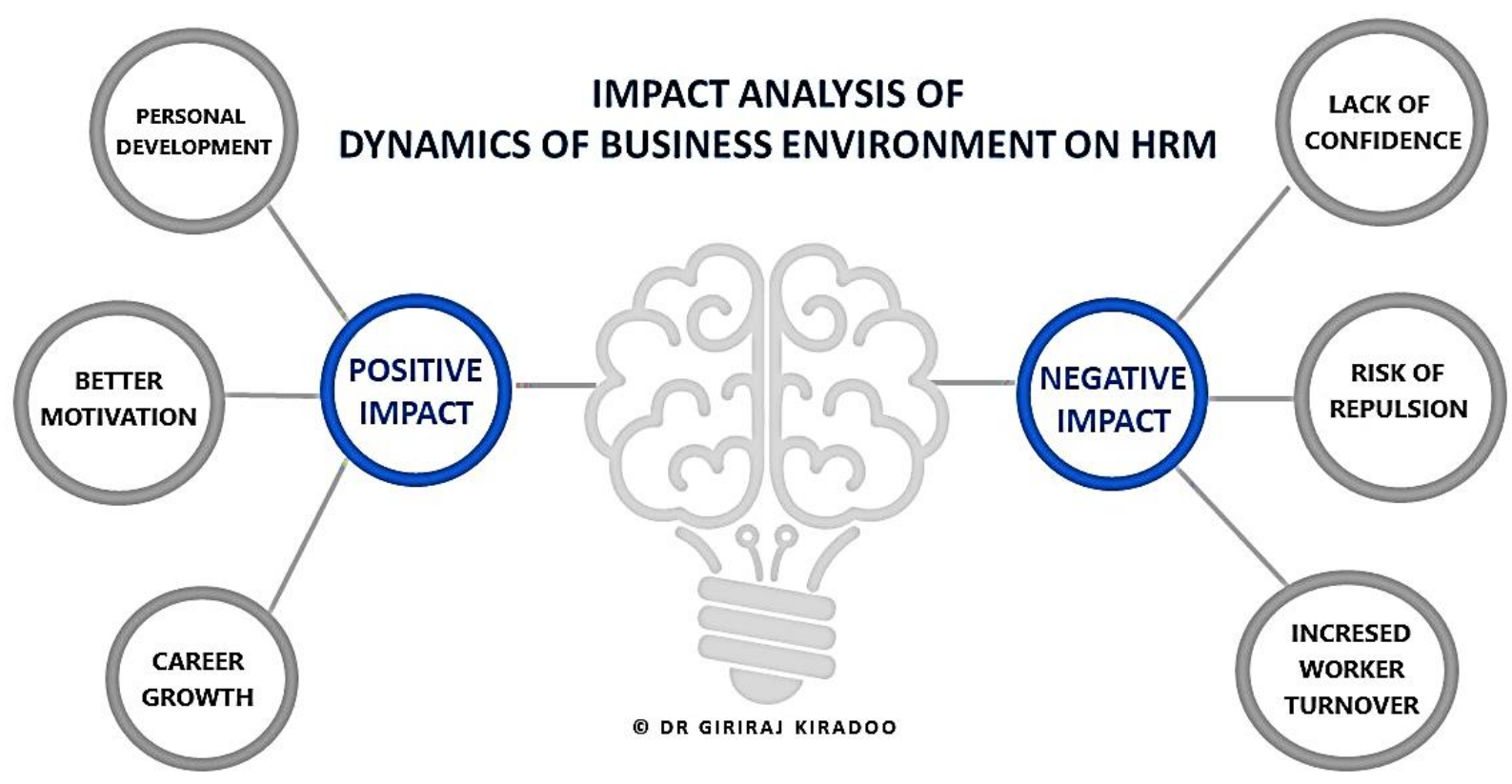

FIGURE: 02

\section{Negative impact on human resources due to changes in the external environment of the business}

\subsection{Lack of Confidence}

It is generally seen that the employee is reluctant to accept the change. There is a danger among employees because they cannot effectively understand the differences, reducing their morale and confidence in their activities and operations (Mudor, 2011). Low confidence is market change and lack of information about the external environment.

\subsection{Low Competition and Risk of Repulsion}

However, employees are less competitive as they do not match the speed of change in the outside environment. It requires the organisation to hire professionals and pose a threat among existing employees from the workplace due to a lack of necessary skills and knowledge sector (Bloom, 2011).

\subsection{Increased Worker Turnover}

Hendry concluded that employees lacked proper employee motivation and confidence, leading to employee business within the organisation. Employees leave the organisation because they cannot handle the workload, and they feel as though their efforts are all to no avail. Lack of decent work and performance improvement result in job dissatisfaction and an increase in turnover rate (Hendry, 2012).

\section{Findings}

Current research focuses on analysing the impact of changes in the business environment on employee performance and business motivation. Human resource management is a crucial area for managing business change and effectiveness. 
The external business environment factors are constantly changing as technological progress and improvement in people's lifestyles. Upgrading technology and increasing competition motivate organisations and managers to adjust to business practices and functions. Managers play a critical role in managing employee training and focusing on changing business tasks, not to feel worthwhile. Motivation is also needed for shaping the staff in the right direction. It has been observed that the positive impact of managing external changes goes beyond the growth of professional development.

There are adverse effects of not adapting and managing organisational change by reducing staff confidence and stiff competition from new players that reduce productivity and customer base. The organisation tries to invest a high number of resources in managing change. Research has shown that it is vital for the firm to apply practical change management principles and adapt employees' behaviour in the right direction. It may also align employees' behaviour according to organisational purposes. These principles bring structural changes to the organisation's performance to achieve the objectives. Management of external change enhances overall organisational productivity and cost-effectiveness by obtaining the right opportunity.

\section{Conclusion}

The research paper ends with the impact of the changing business environment on business operations and performance. Various strategies are adopted by a manager, such as training, motivation, effective leadership, management principles, and support that ensure effectiveness within an organisation. Multiple factors, such as technology, social, cultural, and legal aspects, have affected employees' performance. The changes have both a positive and negative impact on the performance of employees.

\section{References}

1. Ali, Akbar. "Significance of human resource management in organisations: linking global practices with local perspective.” Researchers World Journal of Arts, Science \& Commerce 4, no. 1 (2013): 7887.

2. Boxall, Peter, and John Purcell. Strategy and human resource management. Macmillan International Higher Education, 2011.

3. Bloom, Nicholas, and John Van Reenen. "Human resource management and productivity." In Handbook of labor economics, vol. 4, pp. 1697-1767. Elsevier, 2011

4. Brown, Tim, and Barry Katz. "Change by design." Journal of product innovation management 28, no. 3 (2011): 381-383.

5. Croom, Simon. "Introduction to research methodology in operations management." In Researching operations management, pp. 56-97. Routledge, 2010.

6. Doaei, Habib Allah, and Rahim Najminia. "How far does HRM differ from PM." European Scientific Journal 8, no. 13 (2012).

7. Fujimoto, Yuka, Charmine EJ Härtel, and Fara Azmat. "Towards a diversity justice management model: integrating organisational justice and diversity management." Social Responsibility Journal (2013).

8. Fuhua, Xuan. "Analysis on Strategy of Human Resource Management in Economy Hotel." In International Conference on Information and Management Engineering, pp. 275-279. Springer, Berlin, Heidelberg, 2011.

9. Giriraj Kiradoo, Evaluating the Role of Corporate Human Resource Function in Influencing Global Talent Management (GTM), International Journal of Marketing \& Human Resource Management (IJMHRM), 2(1), 2011, pp. 7-15

10. Giriraj Kiradoo, Exploring the Impact and Influence of Personal and Organisational Values on Forming Organizational Culture and Understanding its Impact on Employee's Commitment and Performance, International Journal of Engineering, Applied and Management Sciences Paradigms, 52(02), 2018, PP 61-66.

11. Giriraj Kiradoo, Exploring the Role of Human Resource Management in Enhancing Organizational Productivity by Offering Professional Support to Employees to Achieve Work-Life Balance, RESEARCH REVIEW International Journal of Multidisciplinary, 01(02), 2016, pp. 30-33.

12. Giriraj Kiradoo, The Role of Motivation of Workforce on the Performance and Productivity of Employees, International Journal of Current Research in Life Sciences, 3(7), pp. 206-209.

13. Hendry, Chris. Human resource management. Routledge, 2012.

14. Jackson, Susan E., Douglas WS Renwick, Charbel JC Jabbour, and Michael Muller-Camen. "State-ofthe-art and future directions for green human resource management: Introduction to the special issue." German Journal of Human Resource Management 25, no. 2 (2011): 99-116. 
15. Long, Choi Sang, Panniruky Perumal, and Akintunde M. Ajagbe. "The impact of human resource management practices on employees' turnover intention: A conceptual model.” Interdisciplinary journal of contemporary research in business 4, no. 2 (2012): 629-641.

16. Mudor, Hamida. "Conceptual framework on the relationship between human resource management practices, job satisfaction, and turnover." Journal of economics and behavioral studies 2, no. 2 (2011): 41-49.

17. Nouri, M., and F. Cortel. "Human Resource Management." Arab Society Library for Publishing and Distribution, Amman (2011).

18. Sarkis, Joseph, Pilar Gonzalez-Torre, and Belarmino Adenso-Diaz. "Stakeholder pressure and the adoption of environmental practices: The mediating effect of training." Journal of Operations Management 28, no. 2 (2010): 163-176. 